\title{
Present significance of resistance to trimethoprim and sulphonamides in coliforms, Staphylococcus aureus, and Streptococcus faecalis
}

\author{
EVELYN L. LEWIS AND R. W. LACEY \\ From the Department of Bacteriology, United Bristol Hospitals, Bristol 1
}

SYNOPSIS The incidence of trimethoprim resistance in coliforms and multiresistant strains of Staphylococcus aureus isolated in Bristol from 1970 to 1972 is low-2.3 and $1.0 \%$ respectively. The resistance is probably intrinsic; there is no evidence that it is $\mathbf{R}$-factor or plasmid mediated. A single mechanism that confers resistance to both trimethoprim and sulphamethoxazole has not been detected. Normal growing one-step mutants of $S$. aureus and Escherichia coli resistant to trimethoprim could not be isolated in vitro. For these reasons cotrimoxazole should retain its usefulness against these bacteria for some years. However, cotrimoxazole was found not to be bactericidal against many coliforms.

The usefulness of cotrimoxazole against Streptococcus faecalis seems limited because mutants resistant to trimethoprim occurred at high frequency in one step.

Since the combination of trimethoprim and sulphamethoxazole (cotrimoxazole) was introduced about four years ago, many reports have shown it to be effective against a variety of bacteria, except Pseudomonas aeruginosa. The initial low numbers of bacteria resistant to both its components gave considerable hope for a long therapeutic future for cotrimoxazole, particularly as resistance to sulphamethoxazole alone does not necessarily impair the synergism between the two drugs in vitro (Bushby, 1969). However, in the last year there have been some reports of organisms resistant to both components of cotrimoxazole. Amongst coliforms, Lacey, Gillespie, Bruten, and Lewis (1972) found that about $2.5 \%$ were resistant to trimethoprim, most also being resistant to sulphamethoxazole. In Streptococcus faecalis, resistance to trimethoprim appears to develop after exposure of the organism to cotrimoxazole in vivo (Chattopadhyay, 1972). In strains of Staphylococcus aureus isolated from hospital sources about $1.6 \%$ are now resistant to both trimethoprim and sulphonamides, with $18.5 \%$ resistant to sulphonamides alone (Nakhla, 1972). Previously no trimethoprim resistance has been reported in this organism. The overall picture, therefore, is of a small but significant increase in bacteria resistant to cotrimoxazole.

In $1971 \mathrm{R}$ factors producing resistance to both Received for publication 22 January 1973. trimethoprim and sulphonamides were detected in coliforms isolated from a few London hospitals (Fleming, Datta, and Grüneberg, 1972); Datta and Hedges (1972) have anticipated a dissemination of this R factor to other hospitals and throughout the coliform population generally. We have been monitoring coliforms isolated in Bristol for the last 18 months for the appearance of such an $R$ factor and have found none. We also report some laboratory studies on the resistance to trimethoprim and sulphamethoxazole which might relate to the usefulness of this combination in the future.

\section{Materials and Methods}

\section{ORGANISMS}

Single colony isolates of coliforms (Gram-negative bacilli; lactose-positive on MacConkey agar), Streptococcus faecalis, and Staphylococcus aureus were obtained during 1970-1972 from clinical specimens initially plated on antibiotic-free medium. The cultures were stored at room temperature on nutrient agar slopes. Strain J53 (Su, Tp) which is a derivative of $E$. coli $K 12$ harbouring an $\mathrm{R}$ factor conferring resistance to sulphonamides and trimethoprim was supplied by Dr N. Datta.

MEDIA

Blood agar was Oxoid blood base no. 2 containing 
$5 \%(v / v)$ lysed horse blood. Antibiotic sensitivity was determined on Oxoid diagnostic sensitivity test (DST) agar containing $5 \%(\mathrm{v} / \mathrm{v})$ lysed blood and stored overnight at $4^{\circ} \mathrm{C}$ before inoculation. Oxoid nutrient broth (no. 2) containing $5 \%$ (v/v) lysed blood (Harper Cawston broth) was used for estimating the minimum bactericidal concentrations (MBCs) of the drugs. In addition, double-strength Difco nutrient broth and agar were used for the cultivation of $S$. aureus.

\section{ANTIBIOTIC SENSITIVITY}

Preliminary testing was done by the use of disks (Lacey et al, 1972) On strains giving absent or reduced zones, minimum inhibitory concentrations (MICs) were determined by the plate dilution method. Inocula were standardized to give about 2.0 colonies in $0.01 \mathrm{ml}$ broth per test organism. Known sensitive and resistant strains were included in each batch. The endpoint was taken as that concentration of either a single drug or combination that prevented any visible growth after 20 hours' incubation at $37^{\circ} \mathrm{C}$. For the determination of MBCs, trimethoprim and sulphamethoxazole were added to Harper Cawston broth the day before inoculation and stored at $4^{\circ} \mathrm{C}$. Ten $\mathrm{ml}$ volumes of the broth were then inoculated with about $10^{5}$ organisms suspended in $0.1 \mathrm{ml}$ broth. After incubation for $24 \mathrm{hr}$ at $37^{\circ} \mathrm{C}$ the broths were subcultured into solid medium. The MBC was defined as the concentration of cotrimoxazole that destroyed $>99 \%$ of the inoculum. In estimating MICs the MBCs of mixtures of trimethoprim and sulphamethoxazole, the ratio of trimethoprim/sulphamethoxazole was 1:20, and generally increased in twofold concentrations.

\section{ATTEMPTS AT TRANSFER OF ANTIBIOTIC}

RESISTANCE IN COLIFORMS

The method was essentially that of Moorhouse and McKay (1968) using mutants of $E$. coli K12 resistant to either rifampicin $(100 \mu \mathrm{g} / \mathrm{ml})$ or nalidixic acid $(50 \mu \mathrm{g} / \mathrm{ml})$ as recipient. Controls included a strain known to transfer tetracycline resistance to this and other recipients. Concentrations of trimethoprim used to detect possible transfer of resistance were $0.5,1.0$, and $5.0 \mu \mathrm{g} / \mathrm{ml}$. For several organisms all three levels were used. In some experiments, other recipients were used; these were rifampicin-resistant mutants of strains recently isolated from different sources.

ATTEMPTS TO DEMONSTRATE LOSS OF TRIMETHOPRIM RESISTANCE IN S.AUREUS AND MUTAGENESIS OF CULTURES Cultures were grown overnight at $42^{\circ} \mathrm{C}$, diluted, and inoculated into nutrient agar plates to give discrete colonies. These were then replicated onto nutrient agar containing $5 \%(\mathrm{v} / \mathrm{v})$ lysed blood and $5 \mu \mathrm{g}$ trimethoprim per $\mathrm{ml}$. The method of mutagenesis of cultures of $S$. aureus and $E$. coli $J 53(\mathrm{Su}, \mathrm{Tp})$ has been previously described (Lacey, 1971).

\section{TRANSDUCTION OF TRIMETHOPRIM}

RESISTANCE IN S. AUREUS STRAIN NO. TPR-A Cultures of the trimethoprim-resistant culture no. TPR-A were induced with mitomycin C. The resultant lysates were checked for sterility, and then irradiated with ultraviolet (UV) light for intervals of up to $5 \mathrm{~min}$ and added to the recipient strain 6936 (for further details see Lacey, 1971). The recipient was then plated on nutrient agar containing $5 \%$ (v/v) lysed blood and $5 \mu \mathrm{g}$ trimethoprim $/ \mathrm{ml}$. After ov incubation, trimethoprim-resistant colonies were examined for sulphonamide resistance by replica plating onto media containing $500 \mu \mathrm{g}$ sulphamethoxazole $/ \mathrm{ml}$.

DEVELOPMENT OF RESISTANCE TO TRIMETHOPRIM BY STRAINS OF E. COLI, STREP. FAE C.ALIS, AND S. AUREUS IN VITRO After assessing the numbers of bacteria by the Miles and Misra method, the test organisms, either from centrifuged broth cultures or directly from plate cultures, were inoculated onto DST agar containing $5 \%$ lysed blood and various levels of trimethoprim. The inoculated plates were incubated for $\mathbf{4 8}$ hours at $37^{\circ} \mathrm{C}$ for $E$. coli and $S$. aureus and 96 hours at $37^{\circ} \mathrm{C}$ for Strep. faecalis.

Trimethoprim lactate and sulphamethoxazole were obtained from Burroughs Wellcome Ltd, Beckenham, Kent.

\section{Results}

TRIMETHOPRIM RESISTANCE IN COLIFORMS From November 1971 to October 1972, a total of 711 strains of coliforms from hospital and non-hospital patients were tested for resistance to trimethoprim by the disk method. All coliform strains were tested during three one-month periods; at other times strains were tested when it was clinically relevant. Of these strains, $16(2.3 \%)$ were resistant to between 2 and $100 \mu \mathrm{g}$ trimethoprim $/ \mathrm{ml}$. Further identification of these organisms showed that three were atypical Klebsiella, four Enterobacter species, and nine Escherichia. Since no property investigated was 0 associated with a particular species, this group of organisms is referred to as coliforms. A similar incidence $(2.5 \%)$ was found in the strains isolated earlier in 1971 (Lacey et al, 1972). Of the 16 strains isolated since November 1971, 13 were also resistant to sulphamethoxazole (MIC $>4000 \mu \mathrm{g} / \mathrm{ml}$ ). The 
sensitivity to cotrimoxazole varied from an MIC of $0.2 \mu \mathrm{g}$ trimethoprim and $4 \mu \mathrm{g}$ sulphamethoxazole/ $\mathrm{ml}$ to $>25.6 \mu \mathrm{g}$ trimethoprim and $512 \mu \mathrm{g}$ sulphamethoxazole/ml. Most strains had MICs near the higher figures.

\section{TRANSFERABILITY OF TRIMETHOPRIM} RESISTANCE

Each trimethoprim-resistant isolate was tested for its ability to transfer this resistance to $E$. coli $K 12$. Six of the isolates were also tested for transfer of resistance to 13 other coliforms. No transfer occurred. These findings are similar to those of Datta and Hedges (1972) who found that transfer of trimethoprim resistance only occurred when the MIC of trimethoprim was $>1000 \mu \mathrm{g} / \mathrm{ml}$.

\section{IS COTRIMOXAZOLE BACTERICIDAL TO}

COLIFORMS AND S. AUREUS?

The correlation of the MIC with the MBC of cotrimoxazole was investigated in $\mathbf{3 0}$ coliforms and 24 strains of $S$. aureus. Although there was a close association of the MIC and MBC in most of the strains of $S$. aureus, a very poor association between these existed for coliforms. The presence of sulphonamide resistance in the latter had little effect on the MBC (table I). In many coliform strains the MBC was > $>500$ times that of their minimum inhibitory concentration. Such a disparity between the MIC and $\mathrm{MBC}$ indicates that cotrimoxazole cannot be considered bactericidal, at least under these conditions. Ratios of trimethoprim to sulphamethoxa- zole other than 1:20 did not produce better cell destruction.

MUTATION TO TRIMETHOPRIM RESISTANCE IN VITRO IN STRAINS OF E. COLI, S. AUREUS, AND STREP. FAECALIS

Darrell, Garrod, and Waterworth (1968) and Bushby (1969) have found that serial transfer of bacteria on media containing trimethoprim can cause the appearance of organisms resistant to high levels of trimethoprim. However, there is no evidence that bacteria acquire resistance by such a process under natural conditions. We have found that repeated subculture of strains of $S$. aureus and $E$. coli in the presence of trimethoprim yields colonies, that although trimethoprim-resistant, have much reduced growth rates and some other defects eg, loss of coagulase production in $S$. aureus. But bacteria develop high-level resistance to streptomycin after a short exposure under natural conditions (eg, Garrod, 1950). Cultures were therefore tested for their ability to give rise to one-step mutants resistant to high levels of trimethoprim. Strains of sulphonamide-sensitive and resistant $E$. coli and $S$. aureus were plated on media containing levels of trimethoprim $10,40,100$, and 250 times that of the corresponding MIC of the strain. Results of these experiments are summarized in table II. Although some colonies grew on each medium, they were slow growing after subculture to antibiotic-free agar, and unstable with only a slight increase in resistance. But from strains of Strep. faecalis, mutants resistant

\begin{tabular}{|c|c|c|c|}
\hline Organism & $\begin{array}{l}\text { Resistance to Sulphamethoxazole } \\
\text { (No. of Isolates) }\end{array}$ & $\begin{array}{l}\text { Range of MIC (fig.) of } \\
\text { Trimethoprim }(T) \text { and } \\
\text { Sulphamethoxazole (S) } \\
\text { (No. of Isolates) }\end{array}$ & $\begin{array}{l}M B C \text { (fig.) Levels of Trimethoprim } \\
\text { (T) and Sulphamethoxazole }(S) \\
\text { (No. of Isolates) }\end{array}$ \\
\hline
\end{tabular}

\begin{tabular}{ll}
\hline & 1 Sensitive \\
Coliforms & (MIC $>32 \mu \mathrm{g} / \mathrm{ml}$ )
\end{tabular}

S. aureus

Coliforms

(3)

2 Moderately resistant

(MIC $64 \mu \mathrm{g} / \mathrm{ml}-256 \mu \mathrm{g} / \mathrm{ml}$ )

S. aureus

(21)

3 Highly resistant

Coliforms

(MIC $512 \mu \mathrm{g} / \mathrm{ml}->4000 \mu \mathrm{g} / \mathrm{ml}$ )

$0.025 \mathrm{~T}+0.50 \mathrm{~S}-0.1 \mathrm{~T}+2.0 \mathrm{~S}$
$0.025 \mathrm{~T}+0.50 \mathrm{~S}-0.1 \mathrm{~T}+2.0 \mathrm{OS}$
$0.1 \mathrm{~T}+2 \cdot 0 \mathrm{OS}-0.4 \mathrm{~T}+8.0 \mathrm{OS}$
$0.1 \mathrm{~T}+2 \cdot 0 \mathrm{~S}-0.4 \mathrm{~T}+8.0 \mathrm{OS}$

$0 \cdot 1 \mathrm{~T}+2 \cdot \mathrm{OS}-0 \cdot 4 \mathrm{~T}+8 \cdot \mathrm{OS}$

$1.6 \mathrm{~T}+32 \mathrm{~S}$

(9) $\begin{array}{ccc} & 0.8 \mathrm{~T}+16 \mathrm{~S} & \text { (3) } \\ & >12 \cdot 8 \mathrm{~T}+256 \mathrm{~S} & (6) \\ \text { (3) } & 0 \cdot 8 \mathrm{~T}+16 \mathrm{~S} & (3) \\ & & \\ & & \\ \text { (4) } & 0.8 \mathrm{~T}+16 \mathrm{~S} & (1) \\ & 3 \cdot 2 \mathrm{~T}+64 \mathrm{~S} & (1) \\ & 12 \cdot 8 \mathrm{~T}+256 \mathrm{~S} & (2) \\ \text { (21) } & 0 \cdot 8 \mathrm{~T}+16 \mathrm{~S} & (8) \\ & 1 \cdot 6 \mathrm{~T}+32 \mathrm{~S} & (5) \\ & 3 \cdot 2 \mathrm{~T}+64 \mathrm{~S} & (6) \\ & 6 \cdot 4 \mathrm{~T}+128 \mathrm{~S} & (1) \\ & 25 \cdot 6+512 \mathrm{~S} & (1)\end{array}$

(15) $\quad 0.1 \mathrm{~T}+2 \cdot \mathrm{OS}$

(2) $\quad 0.8 \mathrm{~T}+16 \mathrm{~S}$

$3 \cdot 2 \mathrm{~T}+64 \mathrm{~S}$

$>12.8 \mathrm{~T}+256 \mathrm{~S}$

Table I Minimum inhibitory concentration (MIC) and minimum bactericidal concentration (MBC) to cotrimoxazole of 30 coliforms and $24 \mathrm{Staph}$. aureus strains sensitive to trimethoprim but of variable resistance to sulphonamides 


\begin{tabular}{|c|c|c|c|c|c|c|c|}
\hline \multirow[t]{2}{*}{ Organism } & \multirow{2}{*}{$\begin{array}{l}\text { No. of } \\
\text { Strains } \\
\text { Tested }\end{array}$} & \multirow{2}{*}{$\begin{array}{l}\text { MIC of } \\
\text { Sulphamethoxazole } \\
(\mu g / m l)\end{array}$} & \multirow{2}{*}{$\begin{array}{l}\text { MIC of } \\
\text { Trimethoprim } \\
(\mu g / m l)\end{array}$} & \multirow{2}{*}{$\begin{array}{l}\text { Proportion of } \\
\text { Inoculum } \\
\text { Producing } \\
\text { Colonies }\end{array}$} & \multirow{2}{*}{$\begin{array}{l}\text { No. of } \\
\text { Colonies } \\
\text { Examined } \\
\text { Further }\end{array}$} & \multicolumn{2}{|c|}{ Properties of Colonies } \\
\hline & & & & & & Growth Rate & $\begin{array}{l}\text { MIC Compared } \\
\text { to Wild Strain } \\
\text { (number) }\end{array}$ \\
\hline E. coli & $\begin{array}{r}12 \\
2\end{array}$ & $\begin{array}{rr}< & 8 \\
> & 256\end{array}$ & $\begin{array}{l}<0.4 \\
<0.4\end{array}$ & $\begin{array}{l}10^{-10}-<10^{-12} \\
10^{-10}-<10^{-12}\end{array}$ & $\begin{array}{l}34 \\
21\end{array}$ & $\begin{array}{l}\mathrm{SC}, \mathrm{U}^{1} \\
\mathrm{SC}, \mathrm{U}\end{array}$ & $\begin{array}{l}\times 1-\times 4 \\
\times 1-\times 4\end{array}$ \\
\hline S. aureus & $\begin{array}{l}2 \\
2\end{array}$ & $\begin{array}{rr}< & 8 \\
> & 256\end{array}$ & $\begin{array}{l}<0.4 \\
<0.4\end{array}$ & $\begin{array}{l}10^{-10}-<10^{-12} \\
10^{-11}-<10^{-12}\end{array}$ & $\begin{array}{l}16 \\
14\end{array}$ & $\begin{array}{l}\text { SC, U } \\
\text { SC, U }\end{array}$ & $\begin{array}{r}\times 1-\times 2 \\
\times 1-\times 4\end{array}$ \\
\hline $\begin{array}{l}\text { Strep. } \\
\text { faecalis }\end{array}$ & 10 & $>4000$ & $<0.5$ & $10^{-5}-<10^{-9}$ & 55 & $\begin{array}{l}\text { Normal } \\
\text { growth }\end{array}$ & $\begin{array}{l}\times 1-4 \\
\times 4-16(11) \\
\times 500\end{array}$ \\
\hline
\end{tabular}

Table II Frequency of mutation to trimethoprim resistance after a single plating on medium containing levels of trimethoprim 10-250 times that of the MIC for each strain

'SC, U denoted small colony growth usually unstable with large, normal growing and fully sensitive colonies appearing at high frequency.

to high levels of trimethoprim were isolated from each medium. The growth rates and cultural characteristics of these mutants resembled those of the wild strains; the resistance was stable over several subcultures.

\section{TRIMETHOPRIM RESISTANCE IN \\ STAPHYLOCOCCUS AUREUS}

Between June 1970 and October 1972, 309 multiresistant strains of $S$. aureus from both hospital and non-hospital sources were tested by the disk method for resistance to trimethoprim. Three $(1.0 \%)$ were resistant. Minimum inhibitory concentrations to the drug of two strains (TPR-A and TPR-B) was 6.4 $\mu \mathrm{g} / \mathrm{ml}$ and $25.6 \mu \mathrm{g} / \mathrm{ml}$ for strain TPR-C. Each was resistant to sulphamethoxazole (MIC $>500 \mu \mathrm{g} / \mathrm{ml}$ and cotrimoxazole (MIC 3.2 $\mu \mathrm{g}$ trimethoprim/ml and $64 \mu \mathrm{g}$ sulphamethoxazole $/ \mathrm{ml}$ ) for strain nos. TPR-A and TPR-B; that for TPR-C was twice these levels). Each isolate was also resistant to penicillin (penicillinase), erythromycin, neomycin, streptomycin, and tetracycline, but sensitive to methicillin, fusidic acid, and gentamicin. The phage patterns were 84 in two and 84/85 in one. In properties, they resemble closely trimethoprim-resistant staphylococci isolated from other hospitals (Nakhla, 1972).

\section{DOES ONE MECHANISM CONFER RESISTANCE TO BOTH TRIMETHOPRIM AND \\ SULPHAMETHOXAZOLE?}

Since both trimethoprim and sulphamethoxazole act on the same biosynthetic pathway (Hitchings, 1969), it is theoretically possible that a single biochemical mechanism can produce resistance to both drugs simultaneously, in which case the same gene(s) will determine both resistances. We have found that sulphonamide resistance in some coliforms may be transferred to $E$. coli $K 12$ without trimethoprim resistance (Lacey et al, 1972). In these organisms the genes determining each resistance must be distinct. The question whether these genes were also different was investigated in a strain of $E$. coli harbouring an $\mathrm{R}$ factor conferring resistance to both drugs (J53 (Su, Tp)) and in two cultures of $S$. aureus. Cultures were treated with a mutagen (nitrosoguanidine) and examined for loss of trimethoprim resistance by replica plating. About $0.1 \%$ colonies of each strain became trimethoprim sensitive (table III). Although some of these were also sulphonamide sensitive, at least one colony fully sensitive to trimethoprim (MIC $0.1 \mu \mathrm{g} / \mathrm{ml}$ ) and resistant to sulphamethoxazole (MIC > 500 $\mu \mathrm{g} / \mathrm{ml}$ ) was obtained from each strain. The mutants resembled the wild strains in other properties. Thus the gene(s) coding for resistance to the two drugs are distinct in the three strains. It is interesting to note that whenever trimethoprim resistance was lost, the MIC of the culture to cotrimoxazole became sensitive regardless of the level of resistance to sulphonamide (table III).

\section{CHROMOSOMAL LOCUS OF GENES}

\section{DETERMINING TRIMETHOPRIM RESISTANCE}

IN $S$. A UREUS

Because staphylococcal plasmids may be lost after growth at $43^{\circ} \mathrm{C}$ (eg, May, Houghton, and Perrett, 1964), strain nos. TPR-A, TPR-B, and TPR-C were grown overnight at $43^{\circ}$ and then examined for loss of trimethoprim resistance by replica plating. No loss of resistance was found amongst 22000 colonies of strain no. TPR-A, 5000 of TPR-B, and 9500 of TPR-C. The stability of the resistance after growth at $43^{\circ} \mathrm{C}$ suggested a chromosomal locus for the genes in question. This was confirmed in strain no. TPR-A by transduction. Cultures of strain no. TPR-A were induced with mitomycin $\mathrm{C}$ and the resultant lysate irradiated with ultraviolet light for various intervals and then added to the recipient (strain 6936). The transduction frequency from the unirradiated lysate was low $\left(2 \times 10^{-9}\right)$ but after 


\begin{tabular}{|c|c|c|c|c|}
\hline Strain & $\begin{array}{l}\text { MIC to Trimethoprim } \\
(\mu \mathrm{g} / \mathrm{ml})\end{array}$ & $\begin{array}{l}\text { MIC to Sulphamethoxazole } \\
(\mu \mathrm{g} / \mathrm{ml})\end{array}$ & $\begin{array}{l}\text { MIC to } \\
(\mu g / m l)\end{array}$ & Co-Trimoxazole \\
\hline $\begin{array}{l}\text { E. coli J53 (Su Tp) wild } \\
\text { Mutant } 1 \\
\text { Mutant } 2 \\
\text { Mutant } 3 \\
\text { Mutant } 4 \\
\text { Mutant } 5 \\
\text { Mutant } 6 \\
\text { Mutant } 7\end{array}$ & $\begin{array}{r}>1000 \\
0.4 \\
0.4 \\
0.1 \\
0.4 \\
0.4 \\
0.4 \\
0.4\end{array}$ & $\begin{array}{r}>4000 \\
128 \\
128 \\
>4000 \\
2 \\
2 \\
>4000 \\
64\end{array}$ & $\begin{array}{l}6.4 \mathrm{~T} \\
0.1 \mathrm{~T} \\
0.1 \mathrm{~T} \\
0.025 \mathrm{~T} \\
0.025 \mathrm{~T} \\
0.025 \mathrm{~T} \\
0.1 \mathrm{~T} \\
0.025 \mathrm{~T}\end{array}$ & $\begin{array}{l}+128 S \\
+\quad 2 S \\
+\quad 2 S \\
+0.5 S \\
+0.5 S \\
+0.5 S \\
+\quad 2.0 S \\
+0.5 S\end{array}$ \\
\hline $\begin{array}{l}\text { S. aureus TPR-A wild } \\
\text { Mutant } 1 \\
\text { Mutant } 2 \\
\text { Mutant } 3 \\
\text { Mutant } 4 \\
\text { Mutant } 5 \\
\text { Mutant } 6 \\
\text { Mutant } 7\end{array}$ & $\begin{array}{l}25 \cdot 6 \\
1 \cdot 6 \\
0 \cdot 4 \\
0 \cdot 4 \\
0 \cdot 1 \\
1 \cdot 6 \\
3 \cdot 2 \\
0 \cdot 1\end{array}$ & $\begin{array}{r}>512 \\
128 \\
128 \\
4 \\
256 \\
>512 \\
128 \\
32\end{array}$ & $\begin{array}{l}6.4 \mathrm{~T} \\
0.4 \mathrm{~T} \\
0.2 \mathrm{~T} \\
0.2 \mathrm{~T} \\
0.2 \mathrm{~T} \\
0.8 \mathrm{~T} \\
1.6 \mathrm{~T} \\
0.1 \mathrm{~T}\end{array}$ & $\begin{array}{l}+128 S \\
+\quad 8 S \\
+\quad 4 S \\
+\quad 4 S \\
+\quad 4 S \\
+\quad 16 S \\
+\quad 32 S \\
+\quad 2 S\end{array}$ \\
\hline $\begin{array}{l}\text { S. aureus TPR-B wild } \\
\text { Mutant } 1\end{array}$ & $\begin{array}{l}6 \cdot 4 \\
0 \cdot 1\end{array}$ & $\begin{array}{l}>4000 \\
>4000\end{array}$ & $\begin{array}{l}3 \cdot 2 \mathrm{~T} \\
0 \cdot 1 \mathrm{~T}\end{array}$ & $\begin{array}{r}+\quad 64 S \\
+\quad 2 S\end{array}$ \\
\hline
\end{tabular}

Table III Properties of trimethoprim-sensitive mutants of E. coli J53 (SU,TP) and two strains of Staph. aureus $(T P R-A$ and $T P R-B)$

ultraviolet irradiation the frequency rose to a maximum of $3.2 \times 10^{-6}$ (table IV). Such stimulation of the frequency is indicative of chromosomal genes (Arber, 1960; Asheshov, 1966).

\begin{tabular}{ll}
\hline $\begin{array}{l}\text { Duration of Exposure of } \\
\text { Lysate to Ultraviolet Light } \\
\text { (Min) }\end{array}$ & Transduction Frequency \\
\hline 0 & $2.0 \times 10^{-8}$ \\
0.5 & $4.5 \times 10^{-7}$ \\
1 & $3.2 \times 10^{-6}$ \\
2 & $4.0 \times 10^{-7}$ \\
5 & $6.8 \times 10^{-8}$ \\
\hline
\end{tabular}

Table IV Increase in the frequency of transduction of trimethoprim resistance from $\mathrm{S}$. aureus strain $T P R-A$ by ultraviolet light

${ }_{1}$ Expressed as the number of colonies per phage particles (titred against strain 6936) in the unirradiated lysate.

About $1.2 \%$ of the trimethoprim-resistant transductants were resistant to $>500 \mu$ g sulphamethoxazole; the remainder were as sensitive as the recipient. This suggests that although the genes determining resistance to sulphonamides and trimethoprim, although distinct, are linked. Similar conclusions may be drawn from the results following nitrosoguanidine treatment (table III) when several of the trimethoprim-sensitive mutants were sensitive to sulphamethoxazole (nitrosoguanidine causes high rates of comutation of adjacent genes: Guerola, Ingraham, and Cerdá-Olmedo, 1971).

\section{Discussion}

In trimethoprim-sensitive strains of $E$. coli and $S$. aureus moderate or even high levels of resistance to sulphonamides have little influence on either the MIC or MBC of cotrimoxazole compared with those of sulphonamide-sensitive .cultures. But resistance of an organism to moderate levels of trimethoprim (MIC about $6 \mu \mathrm{g} / \mathrm{ml}$ ) and high levels of sulphamethoxazole produces resistance to the combination (eg, MIC about $12 \mu \mathrm{g}$ trimethoprim/ml and $240 \mu \mathrm{g}$ sulphamethoxazole $/ \mathrm{ml}$ ). Since many coliforms and staphylococci are resistant to sulphonamides, the usefulness of cotrimoxazole against these organisms depends on the absence of trimethoprim resistance in sulphonamide-resistant cells.

There is no evidence for a single mechanism that confers resistance to both drugs simultaneously; even in a strain of $E$. coli in which an $\mathrm{R}$ factor gives high-level resistance to both drugs, the genes are distinct. Mutation to trimethoprim resistance in sulphonamide-resistant strains of $E$. coli and $S$. aureus is unlikely to be important under natural conditions. We have been unable to obtain one-step mutants resistant to moderate levels of trimethoprim which are not grossly defective. Although it is possible for resistance to develop by serial transfer in the presence of the drug, there is no evidence that this process occurs in vivo.

None of the coliform isolates could transfer trimethoprim resistance in vitro. Information on the 'epidemiology' of $\mathbf{R}$ factors under natural conditions is scanty, although much is known about their properties in vitro. The possibility that $R$ factors determining high-level resistance to trimethoprim and sulphonamides will spread through the enterobacteriaceae as suggested by Datta and Hedges(1972) remains a threat, but has not happened yet, at least in Bristol. The resistance to trimethoprim in these 
coliforms and staphylococci is probably intrinsic, present in a minority of strains. The incidence of these resistant isolates may be expected to increaseprobably slowly-with the use of cotrimoxazole. The three trimethoprim-resistant strains of $S$. aureus described here are very similar in properties to those described by Nakhla (1972). All could have evolved from a single clone. The gene(s) determining trimethoprim resistance is chromosomal in strain no. TPR-A and probably also in strains TPR-B and TPR-C. If the genetic locus for trimethoprim resistance in all staphylococci is chromosomal, this might explain why trimethoprim resistance has not 'spread' to other staphylococci. Chromosomal genes are transferred between cultures of $S$. aureus at much lower frequencies than plasmid genes (Lacey, 1972a). Fortunately trimethoprim-resistant strains are sensitive to methicillin; methicillin resistance is unlikely to be transferred to other strains (Lacey, 1972b). Based on these findings in vitro, strains of $S$. aureus should be expected to retain their sensitivity to either cotrimoxazole or methicillin for some time to come.

In contrast, the value of cotrimoxazole in treating infections due to Strep. faecalis seems limited. Chattopadhyay (1972) showed that strains of Strep. faecalis developed resistance to cotrimoxazole during therapy with this drug; the reason for this would seem to be the frequent occurrence of mutants of Strep. faecalis which possess resistance to trimethoprim.

We thank Professor W. A. Gillespie for initiating this work and providing the cultures, and the
United Bristol Hospitals for a grant from their research funds.

References

Arber, W. (1960). Transduction of chromosomal genes and episomes in Escherichia coli. Virology, 11, 273-288.

Asheshov, E. H. (1966). Chromosomal location of the genetic elements controlling penicillinase production in a strain of Staphylococcus aureus. Nature (Lond.), 210, 804-806.

Bushby, S. R. M. (1969). Combined antibacterial action in vitro of trimethoprim and sulphonamides. Postgrad. med. J., Suppl., 45, 10-18.

Chattopadhyay, B. (1972). Trimethoprim-sulphamethoxazole in urinary tract infection due to Streptococcus faecalis. J. clin. Path., 25, 531-533.

Darrell, J. H., Garrod, L. P., and Waterworth, P. M. (1968). Trimethoprim: laboratory and clinical studies. J. clin. Path., 31, 202-209.

Datta, N., and Hedges, R. W. (1972). Trimethoprim resistance conferred by $\mathrm{W}$ plasmids in enterobacteriaceae. J. gen. Microbiol., 72, 349-355.

Fleming, M. P., Datta, N., and Grủneberg, R. N. (1972). Trimethoprim resistance determined by $R$ factors. Brit. med.J., 1, 726-728.

Garrod, L. P. (1950). Acquired bacterial resistance to chemotherapeutic agents. Bull. Hyg. (Lond.), 25, 539-554.

Guerola, N., Ingraham, J. L., and Cerdá-Olmedo, E. (1971). Induction of closely linked multiple mutations by nitrosoguanidine. Nature [new Biol.], 230, 122-125.

Hitchings, G. H. (1969). Species differences among dihydrofolate reductases as a basis for chemotherapy. Postgrad. med. J., Suppl., 45, 7-10.

Lacey, R. W. (1971). Transfer of tetracycline-resistance between strains of Staphylococcus aureus in mixed cultures. J. gen. Microbiol., 69, 229-237.

Lacey, R. W. (1972a). Transfer of chromosomal genes between staphylococci in mixed cultures. J. gen. Microbiol., 71, 399-401.

Lacey, R. W. (1972b). Genetic control in methicillin-resistant strains of Staphylococcus aureus. J. med. Microbiol., 5, 497-508.

Lacey, R. W., Gillespie, W. A., Bruten, D. M., and Lewis, E. L. (1972). Trimethoprim-resistant coliforms. Lancet, 1, 409-410.

May, J. W., Houghton, R. H., and Perret, C. J. (1964). The effect of growth at elevated temperatures on some heritable properties of Staphylococcus aureus. J. gen. Microbiol., 37, 157-169.

Moorhouse, E. C., and McKay, L. (1968). Hospital study of transferable drug resistance. Brit. med. J., 2, 741-742.

Nakhla, L. S. (1972). Resistance of Staphylococcus aureus to sulphamethoxazole and trimethoprim. J. clin. Path., 25, 708-712. 